\title{
Lubrication system of a roller cone bit
}

\author{
Denis Simisinov ${ }^{1, *}$, Anatoly Afanas'ev ${ }^{1}$, Vitaliy Adas ${ }^{1}$, and Anton Simisinov ${ }^{2}$ \\ ${ }^{1}$ Ural State Mining University, 620144, 30 Kuibyshev street, Ekaterinburg, Russia \\ ${ }^{2}$ Ural Federal University. 620002, 19 Mira street, Ekaterinburg, Russia
}

\begin{abstract}
For drilling roller bits that work with face purging, a device for a circulating lubrication system is proposed through the use of a plunger pump. A constant circulation of the lubricant is realized with a performance proportional to the speed of the bit. The relationship between the parameters of the lubrication system and the purge air pressure with the maximum depth of the well is established. The obtained equations allow us to determine the parameters of the bit journal lubrication system and exclude the penetration of drilling products into the bearing cavity, which will increase the bit life.
\end{abstract}

The use of rolling bearings in the support and obligatory purging of the support to cool its elements and protect it from the ingress of sludge into the support is typical for drilling roller bits that work with face purging.

Since the bearing cannot meet the requirements of strength toughness, temperature stability and low friction, $80 \%$ of roller cone bit failures are due to the early failure of the bearing system $[1,2,3]$. Therefore, it is necessary and urgent to conduct failure analysis of the roller cone bearing and to improve the service life of the roller cone bit.

Drilling roller bits designed for boring drilling and blasting wells are made with purge channels that supply compressed air through the journal to the bearings, and then through the annular gap to the outside of the bit. But the pressure difference created in the support cavity and the bottom of the well is not enough to protect against the penetration of sludge into the bit support. Termination of air supply when drilling is stopped, even if there is a reserve valve, leads to the penetration of sludge into the support through the existing gaps.

The lack of a lubrication system increases heat generation in the bearings. The bearings of the support intensively emit heat, according to the data from paper [2], the total heat power in the bit support can exceed $2 \mathrm{~kW}$.

Using air as a cooling agent is significantly less efficient than using drilling mud. Under comparable conditions, with the same degree of heating, air receives approximately 60 to 100 times less heat than water. Reducing the initial air temperature and humidifying it to provide evaporative cooling can be used as ways to normalize the bit temperature. In all cases, it is recommended to purge the supports [3,4].

The world practice of using drilling roller bits shows that further increase in their performance and reliability should be associated with the improvement of sealed supports.

\footnotetext{
* Corresponding author: $\underline{7 \operatorname{sinov} @ \text { mail.ru }}$
} 
The applied cooling scheme of the bit support by purging does not allow to apply effective solutions (plain bearings, bearing lubrication) used in sealed supports of drilling roller bits.

Drilling roller bits working with face flushing have a sealed oil-filled support with a seal and a channel that provides compensation for oil consumption coming from the lubricator with a compensator for loss of lubrication during the operation of the bit. Under the pressure of the drilling mud entering the compensator through the hole in the cover, the lubricant is pushed through the lubrication channel to the bearings of the support. Loss of lubrication from the roller cavity is prevented by a seal that covers the gap between the roller and the journal.

However, the designs used for oil-filled bearings with lubricators do not ensure the circulation of lubrication in the bit support, which is necessary to remove heat from the contact surfaces of bearings.

Objects of industrial property $[5,6]$ proposed a device for a circulating lubrication system through the use of a plunger pump (Fig. 1). A constant circulation of the lubricant is realized with a capacity proportional to the speed of rotation of the bit.

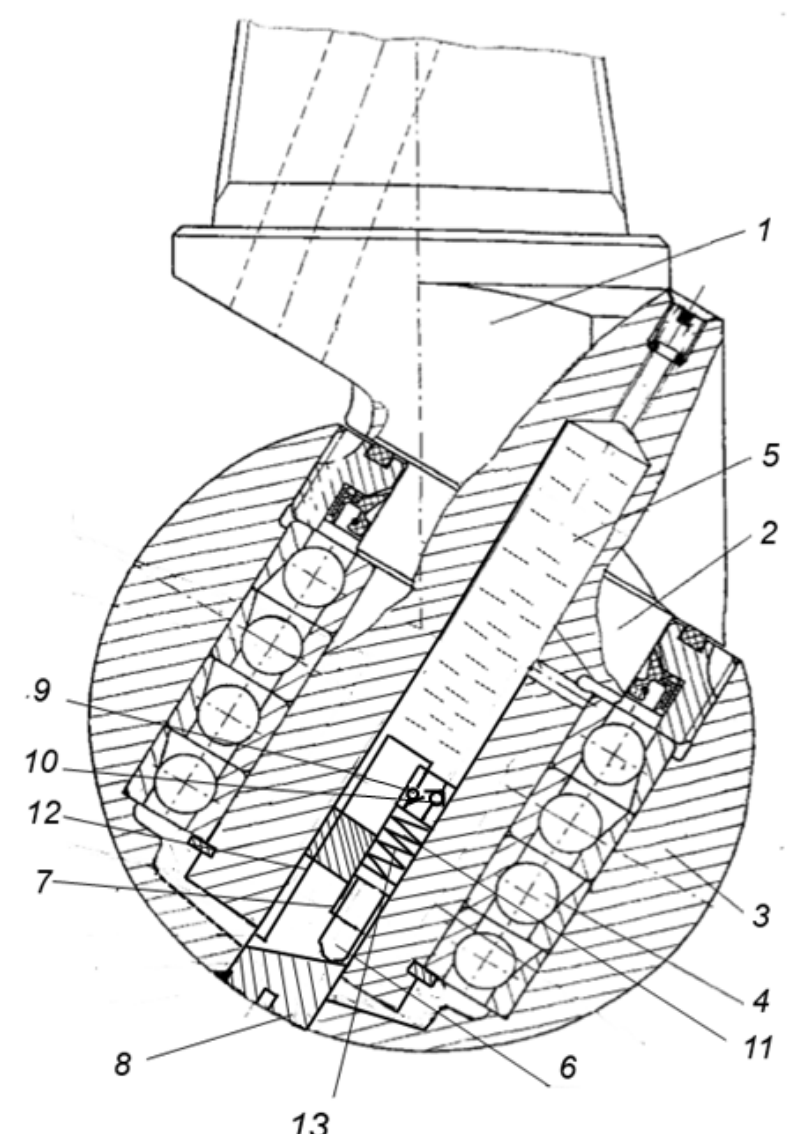

Fig. 1. Circulating lubrication system: 1 - body; 2 - bearing, 3 - cone, 4 - journals, 5 - lubricator, 6 plunger, 7 - pump case, 8 - taper washer, 9,10 - valves, 11 - spring, 12 - pipeline, 13 - pumping chamber. 
To prevent small particles of rock mass from the well through the sealing cup from entering the bearing cavity, the pressure developed by the plunger pump $\left(p_{p}\right)$ must be greater than the purge air pressure $\left(p_{a}\right)$ in the well.

$$
p_{p}>p_{a}
$$

The practice of bearing operation shows that the excess pressure of $p_{p}$ over the pressure of $p_{a}$ can be assumed to be equal to $15 \ldots 20 \%$.

Considering the path of oil movement from the plunger 6 of the pump, it can be seen that the main hydraulic resistance is the radial hole in the journal 2 , which connects the bearing cavity 4 to the oil reservoir 5 . The amount of hydraulic resistance of this hole depends on the maximum speed of oil movement in it, which in turn is determined by the performance of $Q_{p}$ plunger pump. Using the law of conservation of mass (the equation of continuity of the flow), we determine the speed of oil movement in the hole

$$
V_{\mathrm{m}}=V_{p} \cdot d_{p}{ }^{2} / d_{\mathrm{o}}^{2}
$$

where $V_{\mathrm{p}}-$ speed of plunger movement, $\mathrm{m} / \mathrm{s}$;

$d_{\mathrm{p}}$ - plunger diameter, $\mathrm{m}$;

$d_{0}$ - hole diameter, $\mathrm{m}$.

The total coefficient of local resistances $\zeta_{\mathrm{o}}$ is defined as the sum of the coefficient of resistance when the flow section decreases and the coefficient of resistance when the oil flow expands.

The speed of the plunger movement is determined by the angular velocity $\omega$ of the rotation of the roller 3 , the stroke $S$ of the plunger 6 and the number of protrusions (teeth) $z$ at the end of the taper washer 8

$$
V_{\mathrm{p}}=S \cdot z \cdot \omega / 2 \pi
$$

The plunger stroke is limited by the angle of inclination $\alpha$ of the side surface of the protrusion to the plunger axis (Fig.2).

$$
S=\left(d_{\mathrm{s}} \cdot \sin \alpha\right) / z
$$

where $d_{\mathrm{s}}-$ taper washer diameter 8 .

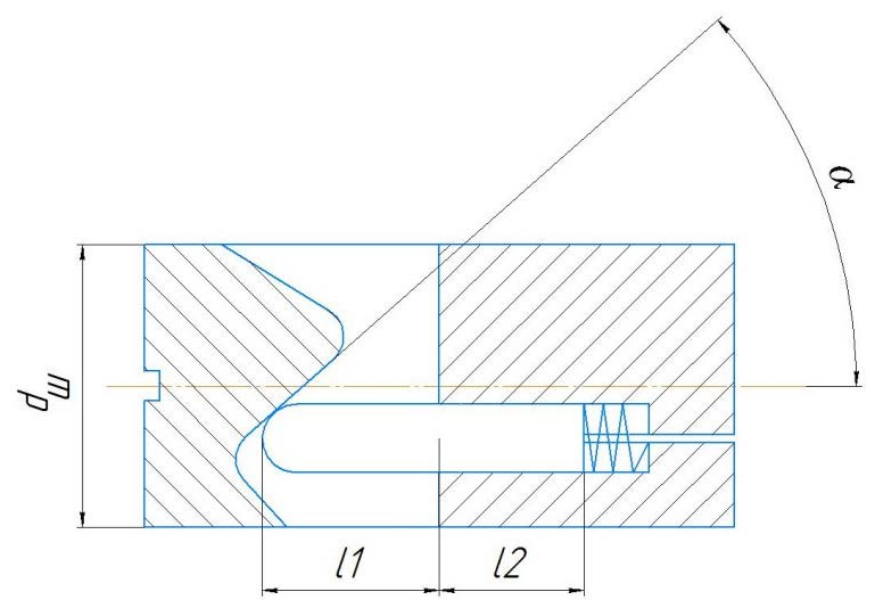

Fig. 2. Plunger hoisting scheme $(z=2)$.

The angle of inclination $\alpha$ of the side surface of the protrusion to the plunger axis (see Fig. 2) must be greater than the friction angle of the pair: steel - steel. 
The limited dimensions of the plunger pump impose certain conditions on its design parameters: the diameter of the plunger, length and stroke.

The plunger 6 movement is possible if the condition is met

$$
\operatorname{tg} \alpha>f\left(2 l_{1}+l_{2}\right) / l_{2}
$$

The purge air pressure $\left(p_{a}\right)$ in the well is determined by the static pressure $\left(H_{c} \cdot g \cdot \rho_{a}\right)$ of the air column with drilling products, depending on the depth $\left(H_{c}\right)$ of the well, the dynamic pressure at the wellhead $\left(0,5 \mathrm{~V}_{a}^{2} \cdot \rho_{a}\right)$ and the loss of pressure $\left(\Delta p_{f}\right)$ on friction.

Thus, it is possible to establish a relationship between the parameters of the lubrication system and the purge air pressure and the maximum depth of the well.

$$
1,2\left[H_{c} \cdot g \cdot \rho_{a}+\left(0,5 V_{a}{ }^{2} \cdot \rho_{a}\right)+\Delta p_{f}\right]=0,5 \cdot \rho_{\mathrm{m}} \cdot \zeta_{\mathrm{o}} \cdot\left[(S \cdot \omega / \pi) \cdot d_{p}{ }^{2} / d_{\mathrm{o}}{ }^{2}\right]^{2}
$$

where $\rho_{m}$ - lubrication consistency, $\mathrm{kg} / \mathrm{m}^{3}$.

$\rho_{a}-$ density of the mixture of air and drilling products, $\mathrm{kg} / \mathrm{m}^{3}$;

$g$ - acceleration of gravity, $\mathrm{m} / \mathrm{s}^{2}$.

Conclusion: using dependencies $2-6$, you can determine the parameters of the bit journal lubrication system and exclude drilling products from entering the bearing cavity, which will increase the bit life.

The study was funded by the Ministry of science and education of the Russian Federation N 08332020-0007 according to the task for the Ural state mining university.

\section{References}

1. Huang, Zhiqiang, and Gang Li. Failure analysis of roller cone bit bearing based on mechanics and microstructure. Journal of Failure Analysis and Prevention 18.2, pp. 342-349 (2018)

2. Zhidovcev N.A., Kershenbaum V.Ya., Ginsburg E.S. Dolgovechnost sharoshechnyh dolot. - Moscow: Nedra, pp. 272 (1992)

3. Esman B.I., Gabuzov G.G. Termogidravlicheskie processy pri burenii skvazhin. Moscow: Nedra. 216 p. (1991)

4. Afanasiev, A.I., Simisinov, D.I., Shestakov, V.S. Equivalent heat model of roller cone bit. Gornyi Zhurnal. Issue 9, pp. 52-56 (2014)

5. Roller cone bit with sealed support RU 199537 U 08.05.2020

6. Roller cone bit with sealed support RU 2453675 C1 13.12.2010 